constant an accompaniment, we are now frequently called upon to combat an amount of disease, the existence of wich, from the negative character of the direct symptoms, has been almost unsuspected by the patient himself. It must have occurred to all to be surprised at the amount of thoracic, as well as abdominal disease, in connexion with inflammation of the serous membranes, which has been found to obtain, while the patieut, farther than feeling weak and somewhat out of health, has scarcely been compelled to forego his usual occupation.

In these cases, if a too lowering treatment be adopted, the necessary reparative powers will incvitably be interfered with; and a cacoplastic, or even tuberculous deposit upon the membrane, with a dirty, shreddy collection of sero-purulent fluids within its cavity, will be the result of the too active remedial interference.

Not only to the diseases to which I have thus in the foregoing observations very cursorily alluded, but also to fevers, pucrperal affections, and the whole extensive range included within the limits of toxamic influence, will similar remarks apply.

In conclusion, I may state, that in troubling you with these observations, it has not been under the impression that I could advance anything novel, but because I have felt, and daily experience convinces me of the fact, that the amount of influence which is exerted upon disense by its prevailing type is not sufficiently regarded. I have been anxious only to instil caution, and to insure reflection, prior to using as a routine necessity the powerfully depressing measures which we possess, and by the indiscriminate adoption of which we expose ourselves to the impertinent inuendos and insinuations of the followers of the leading quackery of the day.

The judicious abstraction of blood by the lancet will unquestionably every now and then be necessary ; but he who will allow himself to regard its use as an exceptional, rather than as a necessary part of the treatment of the majority of diseases as they at present obtain, will prove, I can but think, the most successful practitioner. The tendency of inflammatory affections, particularly of the lung, while it exalts the sensibility of the diseased portion, undoubtedly depresses the system generally. An active eliminative treatment, powerfully operating through the three great channcls of the skin, the bowels, and the kidneys, may, in the majority of cases, be beneficially substituted for general bloodletting.

These measures, by avoiding the unduly lowering the powers of life, and by not interfering with the process of repair, so necessary to the cure, will tend to insure a safe and comparatively short convalescence, free from that depressing debility to which, in the strumous subject, is so frequently to be traced the first commencement of tuberculous cachexia.

Ipswich, July 18:53.

\section{CASE OF RECOVERY AFTER COMPOUND FRACTURE OF THE FRONTAL BONE, AND LOSS OF CEREBRAL SUBSTANCE.}

\section{By GEORGE MALLETT, Fisq.}

TuE following case of severe cerebral injury is, I think, important and intcresting. It proves very decidedly that Vil desperandum ought to be the motto of a surgeon; and it also exhibits in a remarkable manner the wonderful power of nature in repairing injuries that are apparently mortal.

CAsE. R. Booth, aged 60, a stonemason, was struck on the forchead by the handle of a windlass in rapid motion. He was taken up by his fellow labourers quite insensible, and conveyed to his house, about a quarter of a mile from the spot.

The medical gentleman residing in the neighbourhood soon saw him; and considering the case to be utterly hope- less, and that life could not continue many hours, he came to the conclusion that nothing could or ought to be done.

The accident occurred in the afternoon; and on the following morning I was requested to visit the man, as he was still alive.

Upon examination, the frontal bone was found to have received a compound fracture and to be much shattered. The entire breadth of the bone, and from one inch to an inch and a half of its height were driven into the brain. A very considerable quantity of the cerebral matter was adherent to the adjoining parts.*

The man was quite insensible; the breathing was slow and almost stertorous; the pulse slow and full.

I had formerly seen some desperate cases of cerebral injury, which recovered: an account of which was published in the seventh volume of our Transactions. I therefore at once resolved to remove the fractured pieces of bone and give him a chance.

Mr. B., the medical man who had seen the case on the preceding evening, was sent for; but he not being at home, 1 , with the assistance of a medical friend, proceeded to remove the shattered fragments of the frontal bone, some of which were found deeply imbedded in the substance of the brain. Twelve pieces of various sizes were removed, and still the man remained quite insensible to our operations; but on the extraction of the thirteenth, and, as it proved, the last, which was a larger piece and more deeply imbedded than the others, he started up in bed and uttered -no doubt from his accustomed habit, and quite unconscious of what had been going on-an oath. Water dressing was applied, and the head was directed to be kept cold by the constant application of that fluid to the scalp.

I saw him on the following morning, and found him quite sensible, and exhibiting no unfarourable symptoms. I left him in charge of the neighbouring surgeon, requesting that his bowels should, if necessary, be occasionally relieved by a little castor oil ; and we agreed that if any unfavourable symptoms should arise, I should be immediately informed. The only intelligence I had was, that he was gradually advancing towards a restoration to health; and after a few weeks I heard no more of the case, and therefore concluded that all was well.

About three months after the accident, I was greatly surprised and pleased to see the man enter my surgery, having walked from his own home, the distance being from three to four miles. The wound was completely healed by granulations, but had left a most frightful deficiency of bone. The pulsations of the brain were seen immediately under the newly formed skin. His intellect, as far as I could judge, was unimpaired; and the muscular power not at all paralysed. In fact, I may say, as he did, that he was quite well. I never saw him afterwards : but I was quite convinced, and endeavoured to convince him, how precarious his existence must be without the greatest care, from the very delicate and insufficient protection which the anterior portion of the brain possessed, being deprived of so large a portion of the frontal bone, no reproduction of which was: to be expected.

$$
\text { Bolton, July 2nd, } 1353 .
$$

[This interesting case is another illustration of the impropricty of forming an absolutely unfavourable prognosis in certain cases of compound fracture of the skull, even when accompanied by considerable loss of cerebral substance. Recoveries are not at all uncommon, when the bone which is broken is the frontal, and the portion of brain lost belongs to the same region. Confirmation of this remark will be found at p. 375 of our Periscopic Review for 29th April.-EdrTor.]

- The quantity of brain lost could not be accurately estimated, but it was not thought to be less than from one to two tablespoonfuls. 